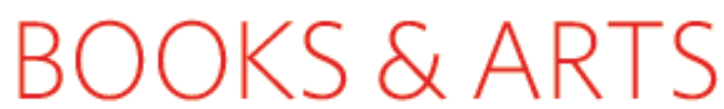

\title{
All the fun of the fare
}

\section{A selection of amusing morsels from the history of nutrition science.}

Terrors of the Table: The Curious History

of Nutrition

by Walter Gratzer

Oxford University Press: 2005.288 pp.

£18.99, \$30

\section{Marion Nestle}

Terrors of the Table is Walter Gratzer's third book on the theme of science as entertaining anecdote. Since his retirement in 2002 from King's College London as a biophysical chemist, he has taken on the less seemly side of the scientific enterprise: the rivalry, envy, delusion, self-deception and outright fraud sometimes committed by researchers ostensibly engaged in the search for truth. As he explained in a radio interview in 2002, his purpose is " to astonish, to instruct and, most especially, to entertain".

And what could possibly be more entertaining than the history of nutrition? This, Gratzer says, is "full of fascination and drama, for it encompasses every virtue, defect, and foible of human nature". To reveal the drama - and a taste of the science that underlies it - he tells some familiar stories. We meet James Lind, who used lemons to counter scurvy; William Beaumont and his fistula patient; Christiaan Eijkman, whose milled rice and chickens revealed so much about beriberi; and a great many others. The stories are replete with sex, religion, suicide, an occasional murder and a riveting cast of characters. Antoine-Laurent Lavoisier, beheaded at the guillotine in the French Revolution, left behind a "highspirited" widow, who married the physicist Benjamin Thomson (later known as Count Rumford). Thomson promoted the nourishing properties of soup and invented the drip coffee pot. The chemist Justus Liebig, Gratzer tells us, was "a giant, often wrong, but seldom in doubt". Albert Szent-Györgyi, who won a Nobel prize for his work on vitamin C, had four wives, two of them 50 years younger than him.

Along with the gossipy details, Gratzer tosses in such diversions as a poem on food adulteration by G. K. Chesterton, and a menu from an 1868 London banquet that lists, among other delectables, "collared horse-head". For readers who might still be interested in the science, an appendix explains the Krebs cycle, glycolysis and inborn errors of metabolism.

The stories are amusing but do not seem to be organized within any particular historical

\section{A taste of history: a Thanksgiving Day dinner innineteenth-century New England.}

or social context. If the book has an underlying message, it is that "the paladins of progress were always up against the forces of reaction". This message is especially evident in the final chapters, in which Gratzer confronts nutrition evangelists, miscreants, vitamin-mongers and the "higher quackery" of food adulterers, diet purveyors and cholesterol zealots. As a modern example, he points to the "hopelessly obfuscated question of salt intake", because its connection to hypertension (except in a "small minority" of individuals) comes down to epidemiology and theology. ${ }^{\alpha}$ There are believers and disbelievers," writes Gratzer, but "the sceptics have won the argument". Really? $\mathrm{He}$ cites a sceptical journalist but ignores research reviews from decidedly secular groups, such as the 2005 US Dietary Guidelines Advisory Committee, that continue to interpret "small minority" as significant and to conclude that populations would be healthier if they ate less salt.

Such casual documentation is the most troubling aspect of Gratzer's anecdotal approach. It seems as though he has read books on nutrition history and written his own Readers Digest-style synopses. Entire sections lack citations, as do many quotations. I loved a comment attributed to Sydney Brenner
- that he "long ago discovered the obesity gene: it is the gene that opens the mouth ${ }^{n}-$ but the book gives no source.

OfJoseph Goldberger, the US Public Health Service officer who identified pellagra as a dietary deficiency, Gratzer writes: "Goldberger's first posting was to a quarantine station, responsible for inspection of ships arriving at the port of Pennsylvania." No footnote is evident but the 'further reading' list mentions Alan Kraut's Goldberger's War (Hill \& Wang, 2003), which I happen to own. Kraut says “Goldberger's first post would be New York" in 1899. He continues: “On April 24, 1900 , Goldberger was reassigned by Surgeon General Walter Wyman to the Reedy Island Quarantine Station at Port Penn, Delaware, the station responsible for inspecting ships seeking entry to the port of Philadelphia (citing a letter from Wyman to Goldberger in 1899). Only the most exacting of scholars will care whether this posting was Goldberger's first or second, but it suggests that the details of Gratzer's book are best taken with a modicum of that theological salt.

Nutritional problems ranging from infant malnutrition to obesity affect vast segments of the world's populations, and are caused as much by political, economic and cultural factors as 
by the lack or excess of nutrients and energy. The many determinants of nutritional status, and the difficulties inherent in figuring out what people eat from day to day, make studies in this field exceptionally challenging. The history of attempts to disentangle the effects of diet from other factors has much to teach us about the ways in which science and society interact. Gratzer's gentle mocking of human frailties makes pleasant reading, but does little to explain the complexity of the issues or the intellectual demands placed on scientists who try to address them. If Gratzer's book does any good at all, it will inspire students to take up this challenge.

Marion Nestle is in the Department of Nutrition, Food Studies, and Public Health, New York University, New York, New York 10012-1172, USA.

\section{Unearthing mammalian origins}

\section{Mammals From the Age of Dinosaurs: Origins, Evolution, and Structure by Zofia Kielan-Jaworowska, RichardL. Cifelli \& Zhe-Xi Luo \\ Columbia University Press: 2005.630 pp. $\$ 195$}

\section{Timothy Rowe}

Palaeontologists may recognize Mammals From the Age of Dinosaurs as an update of an earlier classic, Mesozoic Mammals, edited by Jason Lillegraven, Zofia Kielan-Jaworowska and William Clemens (University of California Press, 1979), a volume of tremendous and lasting impact.

But the new book, for which KielanJaworowska was joined by Richard Cifelli and Zhe-Xi Luo, is twice the length of its predecessor. It is broader in content and scientific scope, and is in many ways a different book altogether. Its increased girth reflects recent areas of scientific advance, including exciting fossil discoveries from across the world, new technologies for analysing them, and changing philosophical perspectives on this defining segment of our own distant past. The book is extensively illustrated, comprehensive and detailed in its treatment of Mesozoic fossils and their primary literature. It presents a broad historical synthesis of early mammalian evolution. And it is likely to become the first book to reach for when embarking on the trail of virtually any question or problem involving deep mammalian history.

The known fossil record of Mesozoic mammals has grown faster in the past 30 years than in the previous 300 . Although overshadowed in the popular media by feathered dinosaurs, more than 200 new Mesozoic species have been named and designated as mammals, and they are profoundly reshaping our knowledge of mammalian structure and evolution. Most of the new names refer to isolated teeth and jaws, but some spectacular discoveries include complete skulls or articulated skeletons, and a few specimens even provide evidence of fur. The three authors of this volume have been directly involved in many of these discoveries, adding authority to this book.

The book overwhelmingly reflects the world view of George Gaylord Simpson, and shows signs of Willi Hennig's influence and the importance of phylogeny reconstruction in interpreting history. But as Isaac Newton proved in deriving the calculus, two variables cannot be optimized in a single equation. The book's architecture thus reflects a struggle that has dominated palaeontology for three decades.
By giving primacy to a simpsonian view, Mammals From the Age of Dinosaurs presents an encyclopaedic work whose thoroughness ensures it will have long and useful life. But its phylogenetic framework is important to its overarching historical synthesis, and that framework was challenged in several papers published by Michael Woodburne and colleagues as this book was nearing completion. Taxon selection, character conceptualization and polarity, and other technical issues will be debated by those in the field as long as this book is read. If the critics are correct, then major structural features of the historical argument may crumble as well. The most important is a fundamental division of mammals into Australosphenidans and Boreosphenidans, and this casts doubt on the authors' interpretations of character history, such as their views on the dual origins of the tribosphenic molar and mammalian middle ear. But even if criticisms of this book's phylogenetic architecture are upheld, it simply highlights that much is yet to be learned about mammalian phylogeny and history.

This beautiful book surpasses all its predecessors in its scope and detail, and in using the most rigorous methods yet directed at such a broad panorama of early mammalian history. Its informative narrative attests that mammalian palaeontology is in the midst of a renaissance of discoveries unexpected 30 years ago. The rich resources gathered between its covers are timely and exciting, and should foster a further boom in mammalian palaeontology.

I am glad to own two copies of this book. It will be the basic mediator of debate for many years to come, and I expect to wear out both copies long before a comparable workemerges to overshadow it.

Timothy Rowe is at the Jackson School of Geosciences, and Texas Mernorial Museum, University of Texas at Austin, Austin,

Texas 78712, USA.

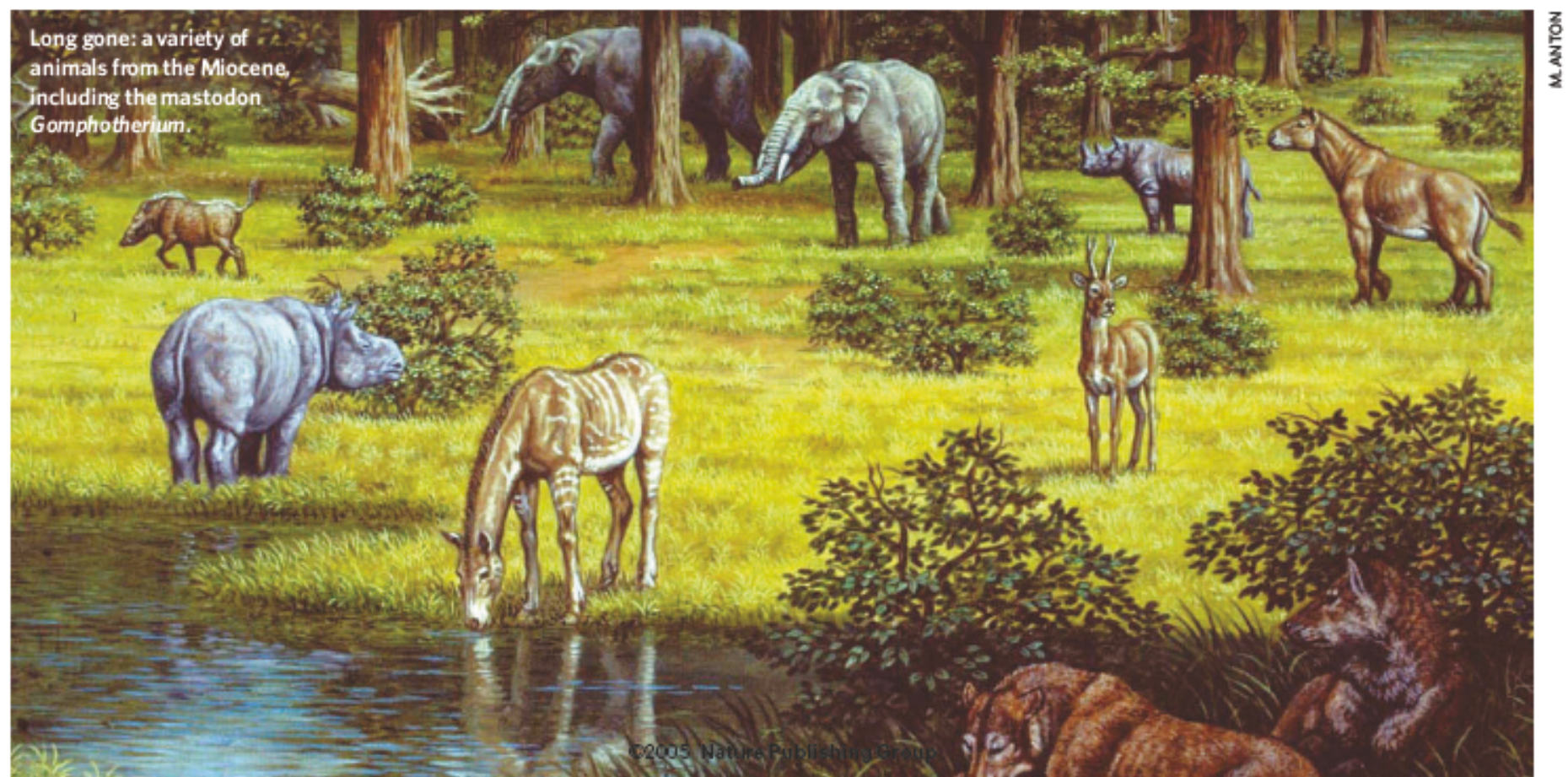

